\title{
Clinical Analysis, Management and Outcome of Intussusception in Children
}

\author{
Thapa B', Chaudhary RP2 ${ }^{2}$ Pun MS ${ }^{3}$, Rai GK ${ }^{4}$ \\ ${ }^{1}$ Dr. Bijay Thapa, MBBS. MS. Registrar Paediatric Surgeon, ${ }^{2}$ Dr. Ramanadha Prasad Chaudhary, MBBS. MS. Consultant \\ Paediatric Surgeon, ${ }^{3}$ Dr. Madhu Sudan Pun, MBBS. MS. HOD and Consultant Paediatric Suregon, ${ }^{4}$ Dr. Ganesh Kumar Rai, \\ Consultant Paediatrician Kanti Children's Hospital, Maharajgunj, Kathmandu, Nepal.
}

Address for correspondence: Dr. Bijay Thapa, E-mail: bijaytapa@hotmail.com

\begin{abstract}
Introduction: Intussusception is the commonest cause of bowel obstruction in infancy and childhood. Early diagnosis and management is essential to reduce morbidity and mortality. The objective was to To review the diagnostic criteria of intussusception in infants and children to increase awareness of attending personnel for effective management decrease the rate of operative treatment and complications. Materials and Methods: The data collected of all 38 patients admitted in Kanti Childrens Hospital between 2008 September to 2009 September were studied prospectively. Each patient was evaluated in regard to age at presentation, sex, signs and symptoms, diagnostic method, treatment (operative, non-operative). Results: During study period of one year there were a total of 20 (52\%) males and 18 (48\%) females of age 3 months to 6 years. Pain abdomen was seen in 25(66\%), vomiting 16(42\%), diarrhea 15(40\%), blood mixed with stool $10(26 \%)$. These symptoms were seen in different combination. X-ray erect abdomen was done in 15 and ultrasound in all 38 cases. Ten out of $15(66.6 \%)$ patients with early presentation and diagnosis had successful barium enema reduction.10 (66.6\%) had successful reduction and admitted to our hospital. $28(74 \%)$ patients were undergone laparatomy. Among 28 (74\%) patents that had lapartotomy, manual reduction was successful in 18 and 10 required bowel resection and anastomosis. Conclusion: The awareness of early features of intussusception is important for early referral to tertiary centers for successful non-operative barium reduction and reduce the need of laparotomies in children.
\end{abstract}

Key words: Barium enema reduction, Children, Intussusception, Laparatomy

\section{Introduction}

ntussusception is a full-thickness invagination of the proximal bowel into the distal contiguous intestine. It is the second most common cause of acute abdominal pain in infants and preschool children after constipation and commonest cause of intestinal obstruction in infants. The proximal invaginating intestine is termed the intussusceptum and distal receiving intestinel (outer part) the intussusciptien. The condition occurs most commonly in the first year of life. lleo-colic (ileum invaginating into cecum or right colon) is the most common type $\mathrm{e}^{1,2,3}$. The primary (idiopathic) type, mostly seen during infancy and childhood, is ascribed to non-specific viral origins.In older children and adults, intussusception is usually secondary to some identifiable intramural or intraluminal pathologies such as polyps and malignancies ${ }^{4}$.
Crampy abdominal pain, vomiting, rectal bleeding (red currant jelly) and abdominal mass are the classic clinical findings of intussusception. Single sign or symptom is more common. Constellation of signs and symptoms is identified only in $10 \%$ of patients. Profound lethargy, dehydration and abdominal distension are also frequent findings ${ }^{1,3,5}$.

Intussusception is usually suspected clinically and the diagnosis is confirmed by either ultrasonography (target or doughnut sign) or contrast enema (fist or coiled-spring sign). When the diagnosis is provisional or confirmed the patient should not be referred for emergency reduction. Before attempting emergency reduction patient should be evaluated for length of symptom and stabilized with intravenous fluid, nasogastric decompression and surgical consultations. 
Urgent operative treatment is not required in all patients with intussusception. Ideally tertiary centre should have the facility of either hydrostatic or pneumatic reduction of intussusceptions because more than $90 \%$ of intussusception in its early stage can undergo successful reduction without surgery ${ }^{8,9,10}$.

\section{Materials and Methods}

This was a prospective study of 38 patients who were diagnosed of intussuception in our out patient and emergency ward and admitted in Kanti Children's Hospital over a period of one year (from September 2008 to September 2009). Patients were evaluated and data collected for age, sex, predisposing factors, signs and symptoms, diagnostic method and treatment (operative, nonoperative).

All the 38 patients were diagnosed based on clinical findings and ultrasonography. Patients who were diagnosed and referred from outside underwent repeat ultrasound Patients with suitable indications underwent barium enema reduction. The selection for barium enema reduction was based on the following criteria: clinical history of less than 48 hours with good general condition of the patient, patients with no abdominal distension, no blood in stool, no signs of peritonitis and shock and no air fluids level in $\mathrm{x}$-ray ${ }^{13,11}$.

Reduction was done by inserting and securing a foleys catheter into the rectum, taping the buttocks together to obtain an occlusive seal and instilling barium into the colon. Under fluoroscopic guidance, pressure applied within the distal bowel pushes the intussuscipiens proximally. Complete reduction was confirmed only when barium freely filled more proximal loops of bowel with reflux into terminal ileum ${ }^{12,13,14}$. Foleys catheter of size 14 and 16 French were used and pressure was maintained with enema can in the height of one meter. A packet barium sulphate was dissolved in one liter of normal saline.

Surgical management was done on those with delayed diagnosis and unsuccessful barium enema reduction. Operation was performed under general anesthesia in a supine position through a right-sided supraumbilical transverse muscle cutting incision. Manual reduction was attempted in all 28 cases. Manual reduction was done by milking back of intussusception by progressive compression of the bowel just distal to it. When manual reduction was not possible or gangrene was already set in, resection of the affected part of the bowel with primary anastomosis was done. The criteria for operative treatment were: Unsuccessful barium enema reduction, clinical history of more than 48 hours, signs of perforation, shock, bloody stool, abdominal distension, hemodynamically unstable and air fluid levels on $\mathrm{x}$-ray.

\section{Results}

A total of 38 patients with the diagnosis of intussusception were admitted over one year period in Kanti Children's Hospital. There were 20 (52.6\%) males and $18(47.4 \%)$ females (Table 1). The age of children ranged from 3 months to 6 years with a mean age of 11 months. 3 months to 12 months old children constituted more than $4 / 5^{\text {th }}(81.6 \%)$ of the cases (Table 2 ).

Table 1: Distribution of cases by sex in chidren with intussusceptions $(n=38)$

\begin{tabular}{|c|c|c|}
\hline Sex & No & Percentage(\%) \\
\hline Male & 20 & 52.6 \\
\hline Female & 18 & 47.4 \\
\hline Total & $\mathbf{3 8}$ & $\mathbf{1 0 0 . 0}$ \\
\hline
\end{tabular}

Table 2: Distribution of cases by age in chidren with intussusceptions $(\mathrm{n}=38)$

\begin{tabular}{|c|c|c|}
\hline Age & No & Percentage (\%) \\
\hline $3 \sim 6 \mathrm{~m}$ & 10 & 26.3 \\
\hline $6 \sim 9 \mathrm{~m}$ & 9 & 23.7 \\
\hline $9 \sim 12 \mathrm{~m}$ & 12 & 31.6 \\
\hline $1 \sim 2 \mathrm{yr}$ & 5 & 13.2 \\
\hline $2 \sim 6 \mathrm{yr}$ & 2 & 5.2 \\
\hline Total & $\mathbf{3 8}$ & $\mathbf{1 0 0 . 0}$ \\
\hline
\end{tabular}

The most common clinical feature was pain abdomen (66.0\%) followed by vomiting (42.0\%) and diarrhea (40.0\%). Forty percent of patients with diarrhea, vomiting and bloody stool were diagnosed as dysentery and discharged from out patients/Emergencies with oral rehhydration solution, metronidazole and antibiotics. Time taken to see the doctor after appearance of first sign/symptom ranged from 5 hours to 2 days. Time taken to diagnose intussusception ranged from 12 hours to 5 days. Among the investigations for diagnosis erect X-ray of abdomen was done in 15 (39.5\%) and ultrasound was done in all $38(100.0 \%)$ cases.

Table 3: Classic clinical findings in chidren with intussusceptions $(n=38)$

\begin{tabular}{|l|c|c|}
\hline Signs/symptoms & No & Percentage (\%) \\
\hline Pain abdomen & 25 & 66 \\
\hline Vomiting & 16 & 42 \\
\hline Diarrhea & 15 & 40 \\
\hline Bloody stool & 10 & 26 \\
\hline
\end{tabular}

Among 38 patients 15 (39.5\%) with early diagnosis and in good general condition were sent for barium enema reduction (table 4). Among them 10 (66.6\%) 
had successful reduction and observed with nil per oral, intravenous antibiotics and fluids for a day or two and then discharged after normal repeated ultrasound, bowel habits and good overall condition condition of the patient.

Table 4: Outcome of non-operative treatment in chidren with intussusceptions $(n=15)$

\begin{tabular}{|l|c|c|}
\hline Outcome & No & Percentage (\%) \\
\hline Successful reduction & 10 & 66.6 \\
\hline Unsuccessful reduction & 5 & 33.3 \\
\hline Total & $\mathbf{1 5}$ & $\mathbf{1 0 0 . 0}$ \\
\hline
\end{tabular}

Altogether 28 cases, 23 who met the criteria for operative treatment and 5 who failed barium enema reduction had emergency laparatomy.

Among the 28 operative cases, 18 (64.2\%) had successful manual reduction and 10(35.8\%) with gangrenous bowel required bowel resection and endto-end anastomosis (Table 5).

Table 5: Methods of operative treatment in chidren with intussusceptions $(n=28)$

\begin{tabular}{|l|c|c|}
\hline Outcome & No & Percentage (\%) \\
\hline Successful reduction & 18 & 64.2 \\
\hline Resection anastomosis & 10 & 35.8 \\
\hline Total & $\mathbf{2 8}$ & $\mathbf{1 0 0 . 0}$ \\
\hline
\end{tabular}

In our series of 38 patients, 28 (74\%) had to undergo surgical treatment.

Table 6: Type of treatment in chidren with intussusceptions $(n=38)$

\begin{tabular}{|l|c|c|}
\hline Treatment type & No & Percentage (\%) \\
\hline Barium reduction & 10 & 26.3 \\
\hline Surgical laparatomy & 28 & 73.7 \\
\hline Total & $\mathbf{3 8}$ & $\mathbf{1 0 0 . 0}$ \\
\hline
\end{tabular}

As the time of diagnosis got longer, the rate of barium enema reduction decreased and laparotomies increased (Table 7). Ten patients (26.3\%) with the history of 2 or more days of signs/symptoms had to undergo resection anastomosis.

\section{Discussion}

Based on the records of Kanti childrens hospital, it has been observed that intussusception remains the top surgical emergency and the leading cause of intestinal obstruction among infants. The mostly affected age group in our study is similar to the reports by several international literatures ${ }^{5,6}$ with $81.6 \%$ patients in our series being under the age of one year. Most studies report more males than females usually at 2:1 or 3:2 ratio but only a slight male predominance is seen in our study. Ravitch claimed that no satisfactory explanation has been offered for this male preponderance.

The most common classic symptom of pediatric intussusception is a sudden onset of severe, colicky, intermittent abdominal pain. However, report from Toronto in 1976 described $15 \%$ of patients with intussusception have no obvious pain abdomen ${ }^{18}$. Both Ravitch and Young found that vomiting was the most common initial symptom ahead of the classic abdominal pain $^{2,8}$.

The signs and symptoms needed to clinically diagnose intussusception should not be difficult as long as one is aware of them. Diagnosis should not be delayed in want of all classic signs and symptoms to be present ${ }^{8}$. Forty percent of our cases with vomiting, diarrhea and bloody stool were misdiagnosed as dysentery and discharged on metronidazole and/or antibiotics resulting in delay in diagnosis. This delay may have potentially serious consequences ${ }^{2,8}$. In our cases, $60 \%$ are diagnosed after more than 48 hours of onset of first signs/symptoms of intussusceptions.

Although intussusception is a clinical diagnosis, ultrasonography is the diagnostic investigation of choice. All 38 patients in our series were confirmed by ultrasound. In 1987, Pracros et al reported 100\% accuracy of ultrasound for the diagnosis of intussusception and

Table 7: Outcome by time of diagnosis in chidren with intussusceptions

\begin{tabular}{|c|c|c|c|c|c|}
\hline \multirow{2}{*}{$\begin{array}{c}\text { Time of } \\
\text { diagnosis }\end{array}$} & \multirow{2}{*}{ No } & \multicolumn{2}{|c|}{ Barium enema } & \multicolumn{2}{c|}{ Laparatomy } \\
\cline { 3 - 6 } & & Successful & Unsuccessful & Reduction & Resection \\
\hline $1 \sim 24 \mathrm{~h}$ & $8(21 \%)$ & $7(87.5 \%)$ & 1 & 1 & 0 \\
\hline $1 \sim 2 \mathrm{~d}$ & $7(18.4 \%)$ & $3(42.8 \%)$ & 4 & 4 & 0 \\
\hline $2 \sim 3 d$ & $7(18.4 \%)$ & Not done & - & 6 & 1 \\
\hline $3 \sim 4 d$ & $6(15.78 \%)$ & Not done & - & 2 & 1 \\
\hline $4 \sim 5 d$ & $6(15.78 \%)$ & Not done & - & 0 & 4 \\
\hline $5 \sim d$ & $4(10.52 \%)$ & Not & - & $\mathbf{1 8}$ & $\mathbf{1 0}$ \\
\hline Total & $\mathbf{3 8}$ & $\mathbf{1 0}$ & $\mathbf{5}$ & & 4 \\
\hline
\end{tabular}


since then this high accuracy rate has been verified by several authors ${ }^{17}$. Ultrasound is an easily available, inexpensive and noninvasive investigationthat is not only helpful in diagnosis of intussusception but also is useful in ultrasound guided barium enema reduction. Other pathology causing intestinal obstruction may also be seen on ultrasound ${ }^{16}$.

All patients in our series were from Kathmandu and near by cities. We get pediatric surgery facility in Kathmandu valley but the condition in remote areas of Nepal is worst.Children are dying without knowing the cause This also shows delayed referral from primary care givers is a major cause of delay in diagnosis and management. Efforts should be made to improve awareness at both referral and primary care centers to promote early referral and management.

Fifteen patients with early diagnosis and presentation in less than 48 hours underwent barium enema reduction. Ten (66.6\%) had successful reduction. Moreover, we found that $87 \%$ of patients diagnosed in less than 24 hours had successful barium enema reduction. Barium enema reduction is the primary treatment of choice in selected cases. To achieve success with this method, certain principles must be vigorously observed. The pre-requisites before attempting reduction are that duration of symptoms should be less than 2 days, there should be no signs of intestinal obstruction on X-ray and there are no signs of localized or general peritonitis ${ }^{13,14}$.

Reduction is confirmed if there is free flow of barium into the terminal ileum, expulsion of faeces and flatus with barium, disappearance of mass and clinically child becomes comfortable. The benefit of this procedure are complete reduction without surgery, no anesthesia required, early ambulation, less stay in hospital and no scar $^{11,12,13}$. But there is always a risk of bowel perforation during the procedure which will worsen the condition. Radiation exposure is also a disadvantage.

A newer mode of therapy introduced by the Chinese is the concept of air pressure enema reduction of intussusception. The indication for this is similar to that of barium enema reduction. The Chinese have claimed a $92 \%$ success rate of reduction ${ }^{13}$.

Twenty eight (74\%) patients in our series had to undergo laparotomy which is a very high rate. It may be due to low socio-economic conditions, a lower literacy and delayed presentation to hospital. This therefore calls for an urgent awareness campaign among medical workers treating children and parents to raise the index of suspicion of, and increase the rate of early presentation in this condition.

\section{Conclusion}

The awareness of early features of intussusception to every physician, medical workers and early referral to centers with pediatric service may reduce delayed diagnosis and unnecessary laparotomies in children with intussusceptions. Patients diagnosed within 24 hours had $87 \%$ successful barium enema reduction in this series, with overall success $66.6 \%$ (10 out of 15 ) among non-operative managangement. Ultrasonography was diagnostic in all 38 cases.

Acknowledgements: I thank all my colleagues and the nursing staff of the paediatric surgical ward of Kanti Children's Hospital.

\section{Funding: None \\ Conflict of Interest: None \\ Permission from IRB: Yes}

\section{References}

1. Jay L. Grossfield, James A O'Neill, Jr.Eric W.Forkalsand. Pediatric Surgery, sixth edition 1313-37,2006.

2. Ravitch MM: Intussusceptions in infants in children. Springfield, IL, Charles C.Thomas, 1959

3. Mary E.Fallat, MD. Intussusception. Pediatric surgery, $3^{\text {rd }}$ ed.518-25, 2000.

4. Courtney SP, Ibrahim N, Longstaff AJ, Davidson CM, Intussusception in adult: Clinical, radiological and histological features. Postgrad Med J 1992;68:449-52.

5. Baracchini A, Chiaravalloti G,Quinti S, Rossi A,Favili $\mathrm{T}$, Ughi $C$ et al.Intestinal intussusception in children. Minerva Pediatr 1995;47;215-9.

6. Daneman A, Alton DJ, Lobo E, et al: Patterns of recurrence of intussusception in children: A 17 year review. Peditr Radiol 1998;28:913-9.

7. Ein $\mathrm{SH}$, Alton D, Paler SB, et al: intussusception in the 1990s: Has 25 year made a difference? Pediatr Surg Int 1997;12:374-6.

8. Young DG: Intussusception. In O'Neill JA Jr, Rowe MI, Grosfeld JL, et al: Pediatric surgery, 5th ed St Louis, Mosby, 1998, pp1185-1995.

9. Mangete ED, Allison AB. Intussusception $\mathrm{n}$ infancy and childhood: An analysis of 69 cases. West Afr J Med 1994;13:87-90.

10. Gudeta B.Intussusception in children: A ten year review. East Afr Med J 199;70:730-1.

11. Dennison WH, Shaker M. Intussusception in infancy and childhood. Brit J Surg 1970:57:679-84. 
12. Ein $\mathrm{SH}$, Stephens CA.Intussusception. 354 cases in 10 years. J Paed Surg 1971;6:16-27.

13. Guo JZ, Ma XX, Zhou QH.Results of air pressure enema reduction of intussusception 6396 cases: 13 years. J Paed Surg 1986;21:1201-3.

14. Rosenkrantz JG, Cox JA, Siverman FN, Martin EW. Intussusception in 1970s: Indication for operation. Paed Surg 1977:12:367-78.

15. Stringer MD, Pablot SM, Brereton RJ: Pediatric iintussusception. Br J Surg 1992;79:867-76.
16. Harrington $\mathrm{L}$, Connolly $\mathrm{BL}$, $\mathrm{Hu} \mathrm{X}$, et al: Ultrasonographic and clinical predictors of intussusception. J Pediatr 1998;132:836.

17. Pracros JP, Tran-Mina VA, Morin DE, et albacore intestinal intussusception in children: Contribution of ultrasonography (145cases). Ann Radiol 1987;30:525-30.

18. Ein SH, Stephens CA, Minor A: The painless intussusception. J Pediatr Surg 1976;11:563.

\section{How to cite this article?}

Thapa B, Chaudhary RP, Pun MS, Rai GK. Clinical Analysis, Management and Outcome of Intussusception in Children. J Nepal Paediatr Soc 2012;32(1):9-13. 